\section{EL SAGRARIO DE DURANA (ÁLAVA). UNA MICROARQUITECTURA EUCARÍSTICA MODÉLICA DE HACIA 1595}

\author{
THE TABERNACLE OF DURANA (ÁLAVA). AN EXEMPLARY EUCHARISTIC \\ MICROARCHITECTURE OF C.1595 \\ DURANAKO SAGRARIOA (ARABA). 1595 INGURUAN EGINDAKO MIKROARKITEKTURA \\ EUKARISTIKO EREDUGARRI BAT
}

RESUMEN: En este artículo se estudia un sagrario romanista que, por sus características arquitectónicas, escultóricas e iconográficas, se puede calificar como ejemplar dentro del panorama artístico alavés de finales del siglo XVI. En esta época se impusieron en la diócesis de Calahorra-La Calzada las nuevas disposiciones tridentinas, que reclamaban una mayor atención a los muebles eucarísticos, y los artistas supieron responder a esa nueva demanda devocional con un nuevo estilo artístico, triunfal, y de clara influencia miguelangelesca, que denominamos Romanismo.

PALABRAS CLAVE: Sagrario; Siglo XVI; romanismo; Trento; Álava; eucaristía; microarquitectura
ABSTRACT: This article focuses on a Romanist a tabernacle which, due to its architectural, sculptural and iconographic characteristics, could be considered exemplary of the artistic context of Alava at the end of the $16^{\text {th }}$ century. At this moment, new regulations from Trento prevailed in the Calahorra-La Calzada diocese, demanding more attention upon Eucharistic furniture, and artists were capable of answering to these devotional demands through a new artistic style. This style, which we call Romanism, was triumphant, showing a clear influence of Michelangelo.

KEYWORDS: Tabernacle; $16^{\text {th }}$ century; Romanism; Trento; Alava; Eucharist; Microarchitecture
LABURPENA:Artikulu honetan sagrario erromanista bat ezagutzera ematen dugu, Arabako XVI. mendearen bukaerako giro artistikoan eredugarria den sagrario bat hain zuzen, dituen ezaugarri arkitektonikoak, eskultorikoak eta ikonografikoak direla eta. Garai honetan Calahorra-La Calzadako elizbarrutian Trentotik etorritako xedapen berriak ezartzen hasi ziren, eta horren ondorioz altzari eukaristikoek garrantzia haundia hartu zuten. Artistek eskaera berri honi erantzuteko estilo berri bat erabili zuten, arranditsua eta Michelangeloren eragin zuzena jasotzen zuena, Erromanismoa deitzen dena.

GAKO-HITZAK: Sagrarioa; XVI. mendea; Erromanismoa; Trento; Araba; eukaristia; mikroarkitektura

\section{ERKIZIA MARTIKORENA, Aintzane}

Universidad del País Vasco (UPV/EHU)

Facultad de Bellas Artes

Barrio Sarriena, $s / n$

48940 Leioa (Bizkaia)

aintzane.erquicia@ehu.eus

ORCID ID: 0000-0002-4661-7079

Este artículo ha sido realizado en el marco del Grupo de investigación (A) del Sistema Universitario Vasco: Sociedad, Poder y Cultura (siglos XIV al XVIII), IT896/16.

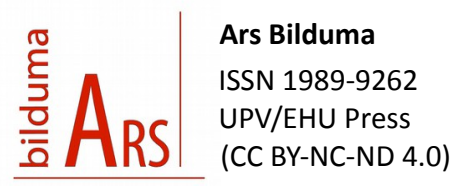

53

https://doi.org/10.1387/ars-bilduma.16893 BIBLID [(2017), 7; 53-69]

Recep.: 20/08/2016 Acept.: 15/10/2016 
Uno de los objetivos de este trabajo es resaltar, y con ello defender, que los tabernáculos eucarísticos de todas las épocas tienen características propias como para ser objeto de estudios monográficos en la disciplina de la Historia del Arte, y más si cabe, los sagrarios realizados al amparo de la contrarreforma, que muestran unas características diferenciadas. Estos muebles, indispensables en cualquier parroquia e independientes de los retablos que los adornan, son piezas fundamentales en la historia del arte y sin embargo su estudio ha estado siempre integrado en el campo de la retablística ${ }^{1}$. Para cumplir este objetivo hemos elegido un sagrario de finales del siglo XVI que, por sus características arquitectónicas, escultóricas e iconográficas, se puede calificar de modélico dentro del panorama artístico alavés de esta época, que es el sagrario de la parroquia de San Esteban de Durana, Álava. En las últimas décadas del siglo XVI se impusieron en la diócesis de Calahorra-La Calzada las nuevas disposiciones tridentinas que reclamaban una mayor atención a los muebles eucarísticos, y los artistas que tenían taller en Álava supieron responder a esa nueva demanda devocional con un estilo artístico triunfal y de clara influencia miguelangelesca, como es el llamado Romanismo, y lo hicieron a través de unas obras con entidad propia como son los sagrarios.

1 Notables excepciones son tres publicaciones clave para los sagrarios del siglo XVI: ARIAS MARTÍNEZ, M.: "El diseño del sagrario contrarreformista: estructura formal, símbolo e iconografía", en CALVO DOMínGUEZ, M. (coord.): Camino de paz. Mane nobiscum domine. Santiago de Compostela, Xunta de Galicia, Consellería de Cultura, Comunicación Social e Turismo, S.A. de Xestión do Plan Xacobeo, 2005, pp. 71-87. BARRÓN GARCÍA, A. Á. y POLO SÁNCHEZ, J. J.: "Los tabernáculos para retablos en el Romanismo burgalés. García de Arredondo", en RUIZ DE LACANAL, Ma D. y GARCíA PAZOS, M. (ed.): La catalogación de retablos. Catalogación, restauración y difusión. Actas de los VIII Encuentros de Primavera en El Puerto. El puerto de Santa María, Ayuntamiento, 2007, pp. 243-278. RAMÍREZ MARTínEZ, J. M.: “El relicario como destacado mueble litúrgico", en LABARGA GARCÍA, F. (ed.): Festivas demostraciones. Estudios sobre las cofradías del Santísimo Sacramento y la fiesta del Corpus Christi. Logroño, Instituto de Estudios Riojanos, 2010, pp. 197-214.
Para explicar por qué el sagrario de Durana es una pieza clave para comprender la importancia de estos muebles en las iglesias alavesas del momento, haremos un primer acercamiento a la iglesia de dicho núcleo, para conocer cuál es la aportación de esta localidad a la historia del arte, analizando posteriormente su tabernáculo, en el que centraremos nuestro análisis en los valores formales, tanto de arquitectura como de escultura, finalizando con su iconografía que, a pesar de su aparente sencillez, es uno de los aspectos más interesantes de este mueble.

\section{DURANA Y SU IGLESIA}

El núcleo de Durana se ubica en el municipio de Arrazua-Ubarrundia, a pocos kilómetros de Vitoria-Gasteiz, en plena llanada alavesa. Su templo parroquial está bajo la advocación de san Esteban protomártir, y es una construcción de nave rectangular de cinco tramos. Fue construida en el siglo XIII en estilo tardorrománico, habitual en la zona de la llanada alavesa que en ese siglo vivió un auge constructivo sin precedentes ${ }^{2}$. Esta iglesia se quedó pequeña a finales de la Edad Media, cuando se produjo un aumento demográfico considerable en toda la provincia, resultado de una época de buenas cosechas ${ }^{3}$. Esto originará importantes reformas en el templo donde, a finales del siglo $\mathrm{XV}$, se derribará la cabecera románica para construir dos tramos más adquiriendo el aspecto que actualmente vemos, terminándose entre 1505 y $1507^{4}$.

2 GARCÍA GUINEA, M. Á. y PÉREZ GONZÁLEZ, J. Mạ: Enciclopedia del Románico en el País Vasco: País Vasco. Aguilar de Campoo, Fundación Santa María la Real, Centro de Estudios del Románico, 2010, tomo 2, pp. 617-626 (texto: Rosalía Holgueras Arranz).

3 LÓPEZ DE OCÁRIZ ALZOLA, J. J.: “El Arte Románico alavés. La gran floración de iglesias románicas y la peculiar configuración de la Álava medieval", Jornadas Congresuales Homenaje a Micaela Portilla Vitoria. Vitoria-Gasteiz, Diputación Foral de Álava, Departamento de Euskera, Cultura y Deportes, 2007, pp. 131-140.

4 ENCISO VIANA, E. (coord.): Catálogo Monumental Diócesis de Vitoria. Tomo IV: La 
El mobiliario que ha llegado hasta la actualidad nos habla de que, a finales del siglo XVI, la iglesia se tuvo que poner al día con las nuevas disposiciones tridentinas que estaban siendo ordenadas desde el obispado de Calahorra-La Calzada, a través de las constituciones sinodales de los obispos que la regían, y de los mandatos de visita. Es el caso del sagrario romanista que tiene la iglesia de Durana, construido hacia 1595 para ser colocado sobre el altar mayor, y que es objeto de atención en este artículo. Para enmarcar el sagrario se construyó posteriormente un retablo mayor, de estilo barroco clasicista, ejecutado por José de Angulo y José de la Plaza a partir de 1642, en cuyas condiciones quedaba reflejado, explícitamente, que el retablo debía integrar en su estructura el sagrario y dos tallas de estilo romanista que tiene la parroquia, una de san Sebastián y otra de san Roque ${ }^{5}$.

En el siglo XVIII se construyeron la sacristía, la torre, el coro y el pórtico exterior, así como los retablos laterales ${ }^{6}$. Finalmente, en el siglo XIX se realizará algún que otro maestreo en la iglesia, que será cuando se aproveche para imponer los gustos estéticos más sobrios y cuando se van a eliminar los colores renacentistas, haciendo desaparecer la pinceladura de los muros ${ }^{7}$ y escondiendo los esgrafiados del sagrario con una pintura plana. El siglo XX también dejará su huella con la eliminación de los retablos laterales y otras obras de arte calificadas de menores como son los textiles. Una historia material que se repite, en mayor o menor medida, en muchas parroquias alavesas.

Llanada alavesa occidental. Vitoria-Gasteiz, Obra Cultural de la Caja de Ahorros Municipal, 1975, p. 331.

5 Archivo Histórico Provincial de Álava-Arabako Artxibo Historiko Probintziala (AHPAAAHP). Prot. 2948, escr. Juan Fernández de Zuazo, año 1643.

6 ENCISO VIANA, E. (coord.): op. cit., p. 333.

7 ECHeVerRía GOÑI, P. L.: "Contribución del País Vasco a las artes pictóricas del Renacimiento: la pinceladura norteña". Ondare, Cuadernos de Artes Plásticas y Monumentales, no 17, 1998, p. 91.

\section{EL SAGRARIO ROMANISTA DE DURANA}

Al tratarse de una iglesia tardorrománica, podemos pensar que, antes de la construcción del tabernáculo romanista, en Durana guardaban las Sagradas Formas en unos nichos practicados en los muros laterales del presbiterio y dispuestos simétricamente, como era habitual en otros templos de la misma cronología como Lasarte, San Vicentejo o Askartza. Durante la Edad Media, los tabernáculos murales fueron la forma más extendida de conservar las Formas consagradas, que consistían en una oquedad abierta en el muro del presbiterio, cerrado con una puerta de rejería y en algunos casos, decorado exteriormente con alguna moldura o algún motivo iconográfico como una Crucifixión o una Piedad. Estos tabernáculos murales se construyeron en un amplio margen de fechas, y en Álava contamos con ejemplares que van desde el siglo XIII hasta el XVI, como los que aún se conservan en Armentia, Grandíval y Caicedo Yuso, entre otros muchos. Aunque no tengamos la seguridad de si estas alacenas eran tabernáculos ${ }^{8}$, credencias $^{9}$ o nichos para reliquias ${ }^{10}$, lo cierto es que en Durana, fue a partir de la construcción del sagrario romanista de madera cuando estos huecos románicos se emplearon como pequeñas capillas, tal y como nos lo muestra la documentación histórica ${ }^{11}$.

8 AIZPÚN BOBADILLA, J.: "Ubicación de los enterramientos y el sagrario. El caso de Estella (Siglos XV y XVI)". Príncipe de Viana, no 228, año 64, 2003, p. 108.

9 La historiografía nombra casi unánimemente estas alacenas como credencias.

10 CASTIÑEIRAS, M.: "San Vicentejo de Treviño, un edificio excepcional en la encrucijada del tardorrománico hispánico", en GONZÁLEZ DE VIÑASPRE GONZALO, R. y GARAY OSMA, R. (ed.): Viaje a Íbita. Estudios Históricos del Condado de Treviño. Treviño, Ayuntamiento del Condado de Treviño, 2011, pp. 249-256.

11 AGUAYO CAMPO, T.: op. cit, p. 156. En 1691 se paga al pintor Diego de Ibarrola "por el Santo Cristo que está en una capilla menor y pintar las capillas menores", que el investigador identifica con los nichos románicos. 
Estos tabernáculos murales y otras formas de guardar las Sagradas Formas fueron considerándose inadecuados e indecorosos a lo largo del siglo XVI cuando la eucaristía recuperó su sentido simbólico asociado a la mesa de altar, y por esta razón las autoridades eclesiásticas fueron instaurando nuevas formas para la reserva eucarística, que son los sagrarios de madera ubicados sobre el altar mayor. A partir de la celebración del concilio de Trento, las constituciones sinodales publicadas en las diócesis $y$, sobre todo, los mandatos de visita, reflejan claramente la necesidad de construir sagrarios que se ajustaran al espíritu tridentino que dotaban a la eucaristía de una importancia troncal en el culto y, por tanto, también en los muebles litúrgicos. En el caso de Durana no podemos asegurar que el sagrario fuese mandado hacer por el visitador de la diócesis, porque no se han conservado los libros de fábrica desde 1532 hasta 1666, ni contamos con libros de visitas, pero el contexto general que se vivía en la diócesis por estas fechas nos hace pensar que se trata de un caso más de renovación del mobiliario litúrgico realizado a la sombra del concilio de Trento.

El sagrario que nos ocupa fue realizado por Esteban de Velasco, cabeza del taller de escultura de Vitoria-Gasteiz entre los años 1595 y 1598. Conocemos el dato gracias a los documentos que proceden de una auditoría realizada por el licenciado Juan Díaz de Arcaya, beneficiado de Durana, con motivo de haber detectado algunos errores en las cuentas de la fábrica por descuidos de los mayordomos, y solicitar una revisión al obispado de Calahorra-La Calzada en el año $1603^{12}$. Mediante este trámite salen a la luz numerosos gastos que la parroquia realiza durante los años 1595 y 1598, entre los que se encuentra un finiquito hecho a Esteban de Velasco por "el relicario", que es la denominación común que se da a los sagrarios en dicha época. También consta en la declaración que se le pagaron 120 ducados por la obra y otros 10 ducados que se le debían, haciendo el escultor remisión y gracia de esta cantidad ${ }^{13}$.

12 AHPA-AAHP. Prot. 6346, escr. Diego Díaz Enríquez, año 1602-1603, fols. 143r-154. La documentación fue sacada a la luz en AGUAYO CAMPO, T.: op. cit., p. 167.

13 AHPA-AAHP, ibid., fol. 150r.
Esteban de Velasco (h. 1550-1602), gran escultor que, a día de hoy, aún no ha sido suficientemente valorado y estudiado ${ }^{14}$, es el maestro que acapara toda la producción de escultura en la llanada alavesa occidental, y quien se encargará de la formación de otros artistas que continuarán con el taller a su muerte. De amplísima y polifacética producción, muestra unas características bastante diferenciadas en los sagrarios que salieron de su obrador y marca un estilo propio que será continuado por otro de los escultores formados por él, como fue Pedro de Ayala, miembro del clan de los Ayala y heredero del taller de su maestro.

El tabernáculo (fig. 1) se encuadra dentro de la tipología de sagrarioexpositor que, junto con el sagrario-relicario, es una de las más frecuentes que podemos encontrar en el siglo XVI. En esta tipología, los muebles cumplen una doble función litúrgica, ya que al mismo tiempo son contenedores y expositores de la reliquia más preciada, la de Cristo Sacramentado. En estos sagrarios que cumplen ambas utilidades el cuerpo inferior se presenta como una caja cerrada con llave, característica de los sagrarios-relicarios, mientras que el superior o superiores se convierten en un templete abierto que se reserva, fuera de las horas de la celebración de la misa, para colocar en él una custodia u ostensorio realizado en materiales nobles, y así exponer la Eucaristía a la vista de los fieles, con la finalidad de estimular su devoción y adoración. Esta tipología de sagrarioexpositor se desarrolla tras la celebración del concilio de Trento, y partir de finales del siglo XVI va a tener una evolución que culminará con los grandes tabernáculos expositores barrocos. Por ello, podemos afirmar que los sagrarios romanistas son los primeros testigos del auge eucarístico tridentino y los que asumen la función de la exposición de la eucaristía, para lo cual cuentan con el cuerpo superior abierto.

14 La investigación más completa y actualizada sobre el escultor lo tenemos en ECHEVERRÍA GOÑI, P. L. y VÉLEZ CHAURRI, J. J.: "La aportación de Esteban de Velasco al romanismo alavés", en ZALAMA, M.Á. y MOGOLLÓN CANO-CORTÉS, P. (coord.): Ars. Estudios de Arte e Historia en homenaje al Dr. Salvador Andrés Ordax. Valladolid, Universidad de Valladolid, Universidad de Extremadura, 2013, pp. 111-120. 


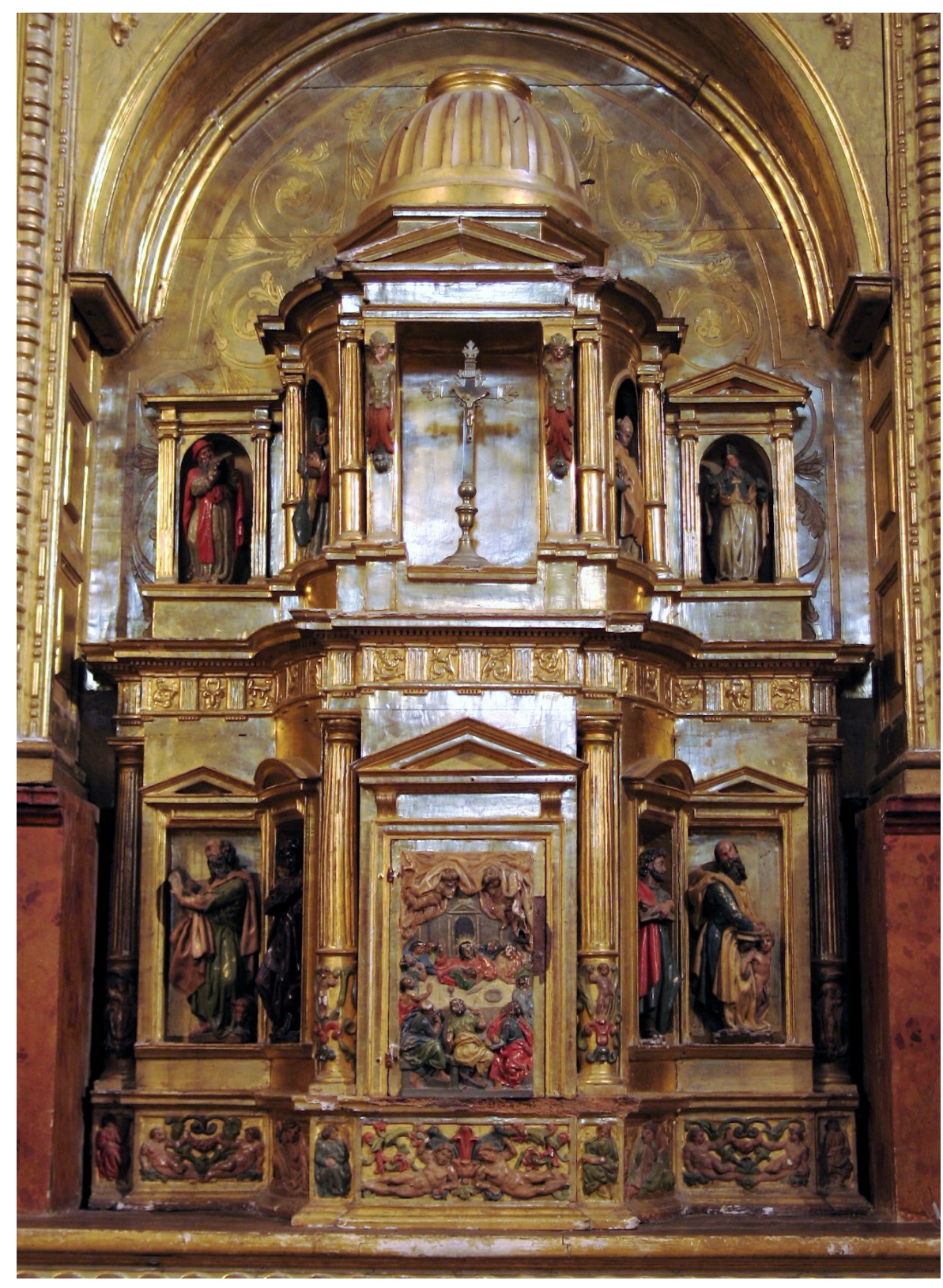

Fig. 1: Sagrario de la parroquia de Durana (Álava)
El templete de la iglesia de Durana es un bello microedificio de estructura de fachada, de planta rectangular con un cuerpo central que sobresale con una ligera curvatura convexa, imitando un edificio de planta central. Se compone de un basamento, dos cuerpos y un remate en cúpula. Su considerable tamaño, -alcanza unos $180 \mathrm{~cm}$ de altura-, hace de este sagrario una potente arquitectura eucarística que destaca en el banco barroco en el que se inserta y que cumple su objetivo de ser el eje visual de la iglesia que acapara toda la atención de los fieles. Se trata de uno de los sagrarios romanistas mejor conservados de la diócesis porque mantiene íntegramente toda su estructura arquitectónica, así como todas sus tallas, aunque la policromía original esté oculta tras una repolicromía lisa.

Todo el sagrario es de un gran clasicismo ordenado y armónico, una microarquitectura que toma como modelos los diseños del Renacimiento italiano. La estructura se articula en base a cajas arquitectónicas con tratamiento independiente, esquema propio del Manierismo, en las que se insertan las tallas de los evangelistas y las de los cuatro Doctores de la Iglesia. Las cajas que los cobijan, en el caso de los evangelistas, son marcos rematados con orejetas de inspiración miguelangelesca, mientras que las de los Padres de la Iglesia son pilastras acanaladas de capitel jónico, rematadas todas ellas por unos frontones que combinan las formas triangular y circular, tal y como los dispuso Miguel Ángel en sus obras arquitectónicas, como se aprecia en la cúpula de la basílica de San Pedro del Vaticano o la Biblioteca Laurenziana, así como en Antonio da Sangallo, el joven, en la fachada del Palacio Farnesio de Roma.

Los soportes empleados en el primer cuerpo son columnas toscanas de fuste acanalado y tercio inferior decorado con relieves, mientras que, en el segundo, ateniéndose Velasco a la superposición de órdenes clasicista que emplea siempre en sus trazas, sostienen el entablamento unas columnas jónicas acanaladas con el tercio inferior liso, y en las cajas de los extremos unas pilastras acanaladas. Coronando todo el microedificio podemos apreciar una cúpula gallonada y ligeramente peraltada, elevada sobre un 
pequeño tambor circular que se apoya en una base poligonal, colocada en $1800^{15}$ en sustitución de la original, hoy perdida, que no sería muy diferente y que estaría rematada por una cruz.

La superficie mural del templete es lisa, sin decoración añadida, aportando una nota de sobriedad y clasicismo que es bastante habitual en las trazas de Esteban de Velasco. Este fuerte sabor clásico y sobrio es la principal característica de los sagrarios realizados entre los años 1580 y 1600 aproximadamente, cuando se desarrolla la época madura del Romanismo en Álava. En la década de los 70, cuando los talleres escultóricos de Valpuesta y Miranda de Ebro introducen el nuevo estilo en la provincia, algunos sagrarios mantienen aún cierta carga decorativa de la fase anterior de la escultura, como podemos ver en los tabernáculos de Ozana (a partir de 1579) realizado por el mirandés Diego de Marquina ${ }^{16}$, o los de Tuesta y Bóveda, tallados por Bartolomé de Angulo, cabeza del taller de Valpuesta ${ }^{17}$. De la misma forma, los sagrarios construidos en las primeras décadas del siglo XVII también van sumando decoración a las estructuras que por estas fechas comienzan a curvarse. En esta fase tardía del Romanismo alavés se imponen estructuras turriformes y con más de dos pisos, fustes entorchados, decoración vegetal más tupida y, junto a ello, también una mayor cantidad de esculturas y que representan temas más variados. Dentro de este grupo de sagrarios tardíos podemos encuadrar los

15 ENCISO VIANA, E. (coord.): op. cit., p. 333.

16 ANDRÉS ORDAX, S.: El foco de escultura romanista de Miranda de Ebro: Pedro López de Gámiz y Diego de Marquina. Valladolid, 1984, pp. 46-51. DíEZ JAVIZ, C.: “El escultor romanista Diego de Marquina (1542-1604)”, López de Gámiz, no XXXII, 1998, pp. 40-41.

17 BALLESTEROS IZQUIERDO, T.: "El retablo del Santo Ángel de la Guarda en la Iglesia de San Pedro de Vitoria", Kultura: cuadernos de cultura, 2a época, no 4, 1992, p. 23. VÉLEZ CHAURRI, J. J. y ECHEVERRÍA GOÑI, P. L.: "El arte religioso del Renacimiento y el Barroco en Valdegovía", en VÉLEZ CHAURRI, J. J. (ed.): Las tierras de Valdegovía. Geografía, Historia y Arte. Actas de las Jornadas de Estudios sobre Geografía, Historia y Arte en Valdegovía. Vitoria-Gasteiz, Diputación Foral de Álava, 2003, pp. 150-152. tabernáculos de Doroño (Treviño) y Payueta ${ }^{18}$, construidas por Pedro de Ayala, el discípulo y heredero del taller de Velasco en Vitoria-Gasteiz y miembro más destacado de esta tercera generación de escultores romanistas alaveses, así como los sagrarios realizados por el navarro Juan Bazcardo, como el de Ozaeta ${ }^{19}$.

Sin embargo, a partir de la presencia de Juan de Anchieta en VitoriaGasteiz en 1575, y hasta los primeros años del siglo XVII aproximadamente, los talleres de Vitoria-Gasteiz y Salvatierra-Agurain, dirigidos respectivamente por Esteban de Velasco y Lope de Larrea, crearán los templetes con carácter más clasicista de toda la época moderna, ya que ensamblarán estructuras a la italiana basándose en diseños arquitectónicos de Bramante, Sangallo, Miguel Ángel o Serlio. El uso ortodoxo de los órdenes clásicos, la presencia de frontones rematando cajas arquitectónicas rectangulares, el predominio absoluto de la línea recta, la estricta superposición de órdenes, los frisos con triglifos y metopas, y la calculada proporción y armonía del conjunto van a ser características habituales de los tabernáculos de estas décadas del Romanismo maduro. Las piezas de Narbaiza y Axpuru, de Lope de Larrea ${ }^{20}$, o las de $\mathrm{Ali}^{21}$, San

18 PORTILLA VITORIA, M. y EGUÍA LÓPEZ DE SABANDO, J.: Catálogo Monumental Diócesis de Vitoria. Tomo II: Arciprestazgos de Treviño, Albaina y Campezo. Vitoria-Gasteiz: Obra Cultural de la Caja de Ahorros Municipal, 1968, pp. 93 y 160.

19 RAMíREZ MARTínEZ, J.M.: Los talleres barrocos de Escultura en los límites de las provincias de Álava, Navarra y La Rioja. Logroño, Diputación Provincial, 1981, pp. 24 y 95-101. PORTILLA VITORIA, M.: Catálogo Monumental Diócesis de Vitoria. Tomo V: la llanada alavesa oriental y valles de Barrundia, Arana, Arraya y Laminoria. VitoriaGasteiz, Obispado de Vitoria, Obra cultural de la Caja de Ahorros Municipal de Vitoria, 1982, p. 665.

20 ANDRÉS ORDAX, S.: El escultor Lope de Larrea. Vitoria-Gasteiz, Diputación Foral de Álava, 1976, pp. 170-180 y 211-212. PORTILLA VITORIA, M.: op. cit., pp. 326-327 y 607.

21 ENCISO VIANA, E. (coord.): op. cit., pp. 177-178. 


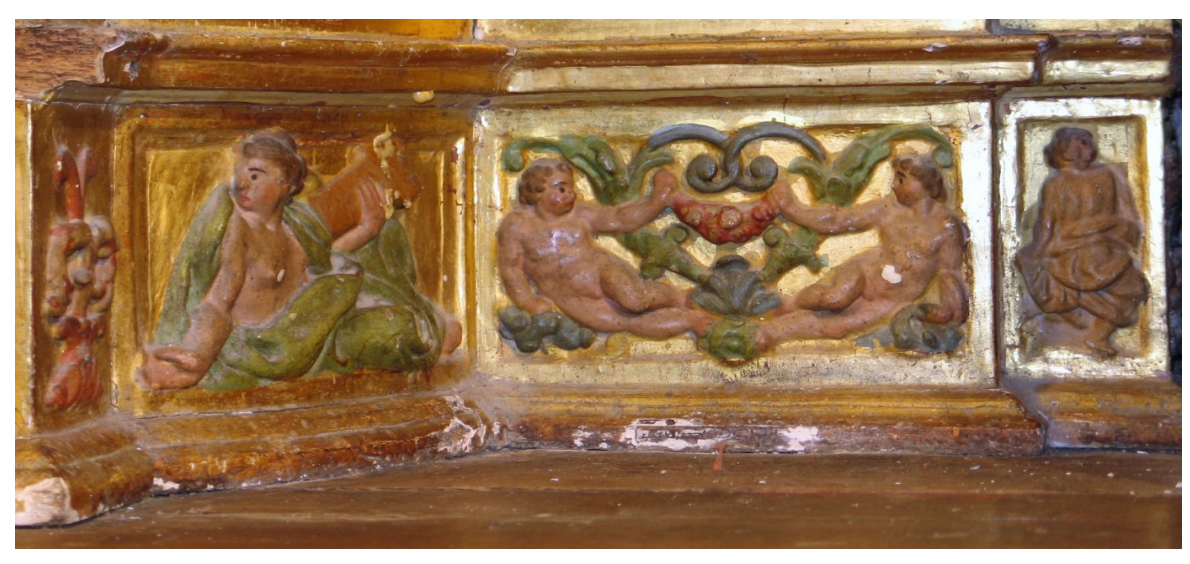

Fig. 2: Basamento del sagrario de Durana (Álava)

Esteban de Treviño ${ }^{22}$ o, sobre todo, la que nos ocupa en este artículo, Durana, realizadas por Velasco, son buenas muestras de ello.

En Durana, por ejemplo, la decoración se reduce al basamento, al tercio inferior de las columnas y al entablamento, en cuyo friso se encuentran triglifos y metopas con la sencilla decoración vegetal que requiere el orden toscano. En el basamento (fig. 2) Esteban de Velasco combina unos ignudi desnudos y recostados en relieve, emparejados y dispuestos simétricamente entre unos rameados mezclados con guirnaldas, con otras figuras femeninas que, sin duda, representan a las virtudes. Estos ignudis aparecen recostados y en una posición que recuerda a las esculturas de la Aurora y el Crepúsculo o el Día y la Noche que Miguel Ángel colocó sobre los sepulcros de los Médici, en la sacristía de la iglesia de San Lorenzo de Florencia, y que tanta repercusión van a tener en el Manierismo europeo.

22 DÍEZ JAVIZ, C.: op. cit., p. 36. TABAR ANITUA, F. (coord.): Catálogo Monumental. Diócesis de Vitoria. Tomo X: Los valles occidentales entre el Zadorra, el Ayuda y el Inglares. La villa de La Puebla de Arganzón. Vitoria-Gasteiz, Fundación Caja Vital Kutxa, 2011, p. 472.
Son modelos que tienen también una fuerte presencia en las obras de Velasco, tanto en sagrarios como en retablos, y que podríamos calificar como una marca de su estilo.

Fig. 3: Hermes del cuerpo superior del sagrario de Durana (Álava)

Otros ignudis, en este caso en postura erguida, decoran el tercio inferior de las cuatro columnas del primer cuerpo. Se trata de unos niños desnudos entre vegetales, elemento éste que podemos ver en otros sagrarios realizados por Esteban de Velasco como el de Pedruzo y San Esteban de Treviño, y que es también una característica propia de este escultor. De hecho, el estilo y la disposición de estas figuras desnudas entre vegetales en las columnas hacen que el sagrario de Pedruzo, obra sin documentar, la podamos atribuir a este artista, ya que esta representación no se repite en otros escultores de sagrarios de Álava.

Mención especial en la decoración merecen los dos hermes membrados que se disponen a ambos lados del expositor del ostensorio (fig. 3). Están apoyados sobre una ménsula avolutada y son dos figuras híbridas, mezcla de hombre y vegetal, con una especie de corona o diadema, igualmente vegetal, que siguen los modelos manieristas de Fontainebleau. A pesar de ser una imagen ampliamente empleada por los artistas manieristas europeos, pocos ejemplares de hermes podemos encontrar en los sagrarios alaveses, tal vez debido a la austeridad general que los caracteriza, por

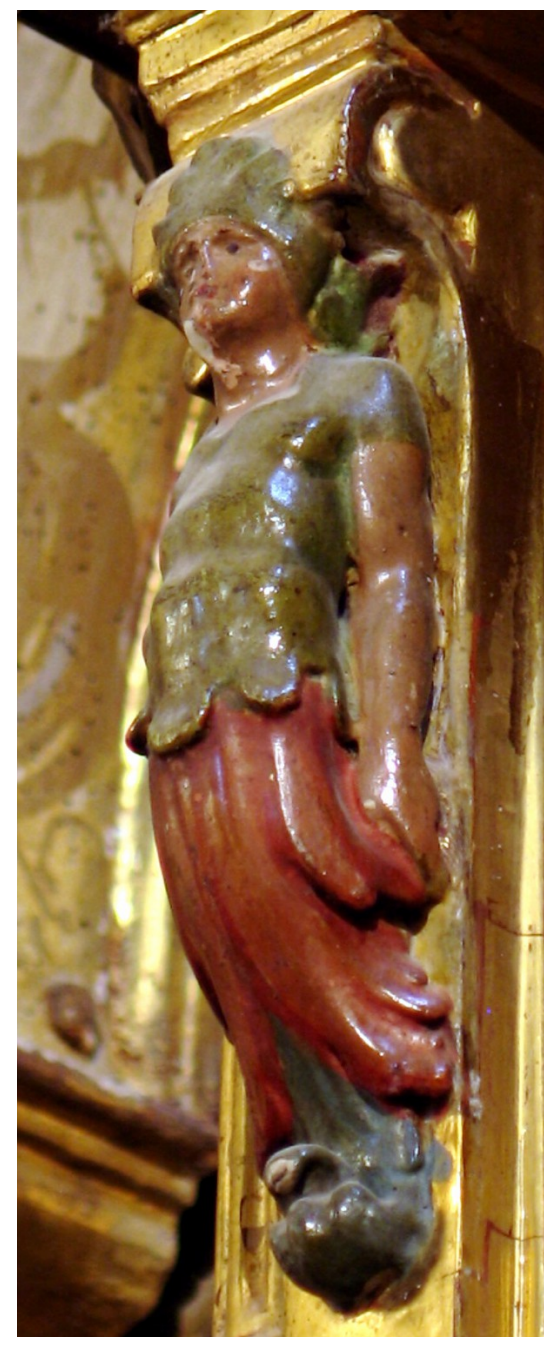


tratarse de una figura poco acorde con el decoro que se exige a los diseños tras Trento o simplemente por tradición artística. Velasco pudo tomar los modelos de la conocida serie de estampas sobre cariátides y hermes de Hans Vredeman de Vries que vieron la luz en Amberes hacia 1565, conservados en la Biblioteca Nacional ${ }^{23}$ (fig. 4), y que ofrecía a los artistas toda una serie de soportes antropomorfos de gran variedad. Asimismo, en la portada del tratado de arquitectura de Sebastiano Serlio, publicado en $1552^{24}$, obra de uso generalizado entre los escultores romanistas de todo el norte peninsular, también podemos encontrar estos soportes (fig. 5).

Volviendo al basamento y en relación a las virtudes que acompañan los ignudis, hemos podido identificar a dos de ellas por mostrar los atributos que las identifican y que están situadas en las dos caras planas a ambos lados del cuerpo central. Una de ellas es la Esperanza, representada como una mujer con el torso descubierto, portando un ancla, su atributo habitual. La otra virtud, enfrentada a ella y ubicada simétricamente en el lado de la epístola del sagrario, es la Fortaleza, también se trata de una mujer con el torso desnudo que se cubre con una amplia túnica, y que sostiene una columna en la mano.

23 VREDEMAN DE VRIES, H.: Caryatidum vulgus termas vocat sive athlantidum multiformium ad quemlibet architecture ordinem ac commodatarum centuria prima in usum huius artis candidatorum artificiose excogitata. Amberes, hacia 1565.

24 SERLIO, S.: Tercero y quarto libro de architectura de Sebastián Serlio Boloñés (...) nuevamente traduzido del toscano en romance castellano por Francisco de Villalpando architecto. Toledo, Juan de Ayala, 1552. Se ha manejado el ejemplar conservado en la Biblioteca de la Universidad de Sevilla, disponible del Portal de Fondos Digitalizados de la Universidad de Sevilla, desde el que se ha tomado la imagen.

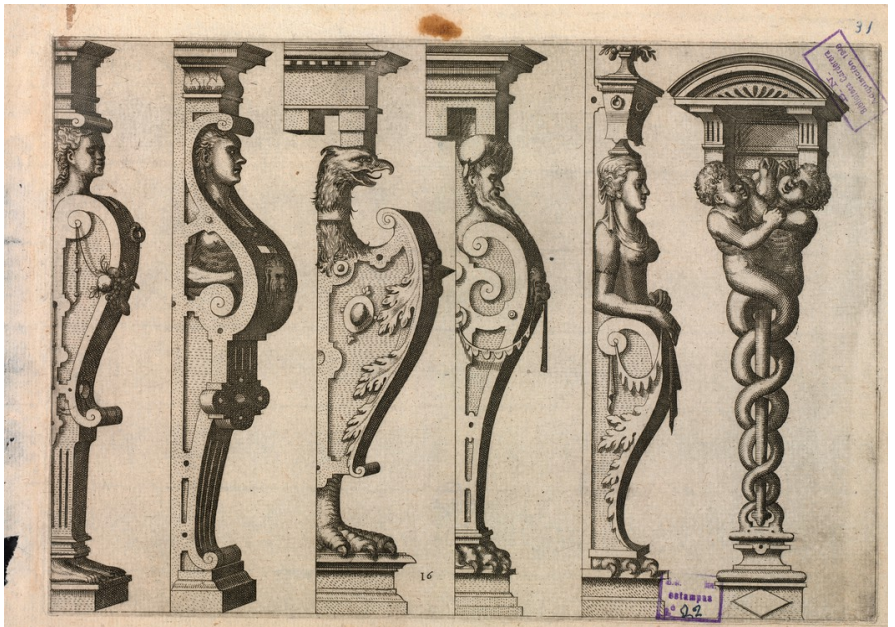

Fig. 4: Hans Vredeman de Vries. Caryatidum vulgus termas vocat... Amberes, hacia 1565. Biblioteca Nacional de España

Fig. 5: Sebastiano Serlio. Tercero y Quarto libro de Architectura. Toledo, Juan de Ayala, 1552 (portada). Biblioteca de la Universidad de Sevilla

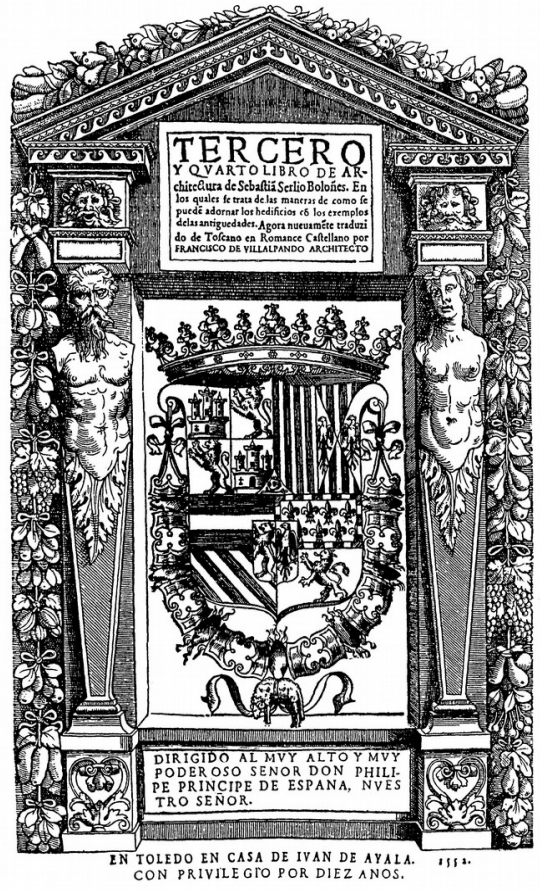

Hay otras cuatro figuras femeninas situadas en los netos de las columnas, en el basamento, que sin duda son las que deben ser otras virtudes, pero nos resulta difícil su identificación al no poder apreciar ningún atributo. Dos de ellas son idénticas en su composición y talla, y representan a una mujer sentada, vestida, que levanta su mano izquierda en un gesto de mostrar algo o señalar hacia arriba. En ambos casos en la talla se advierte una protuberancia, pero el burdo repinte nos impide distinguir de qué objeto se trata, ya que la finura de la talla queda cubierta por la capa de pintura que oculta los surcos que debería tener el relieve. Una de ellas podría ser la representación de la Fe, portando una Hostia, un cáliz o señalando hacia arriba.

Lo mismo se aprecia en las otras dos figuras femeninas. Una de ellas está dispuesta de espaldas y destaca la notoria desatención que mostró el autor 
del repinte cuando la encarnó de nuevo porque, estando mirando hacia su izquierda, es decir, hacia el interior del sagrario y haciendo pareja con las imágenes que están al otro lado, cumpliendo con la simetría y la ley de la correspondencia, le repolicromó el rostro (ojos y boca) en la parte trasera de su cabeza. Su pareja tiene una vigorosa postura miguelangelesca con el hombro en escorzo, pero no tiene ningún atributo.

La disposición de todos estos relieves de ignudis y virtudes guardan un orden específico, ya que las figuras masculinas ocupan los espacios frontales, los correspondientes a las calles del microedificio, mientras que las virtudes se ubican en la parte del basamento del cuerpo central que acoge la caja del sagrario y en los netos de las columnas. Por lo tanto, se observa que la ubicación de estas figuras nos habla de la jerarquía del espacio arquitectónico del sagrario, en el que las virtudes se ubican en las partes estructurales -y por ello más importantes-, y los ignudis en las partes que podríamos llamar de "relleno", cumpliendo una función meramente decorativa.

En lo referente a las esculturas que contiene tan magnífica arquitectura, debemos decir que son unas buenas muestras del estilo de Esteban de Velasco, caracterizado por una anatomía marcada, con unos rostros de ceño fruncido, con los labios apretados, gestos de seriedad y autoridad, con los cabellos ensortijados y las barbas largas y bífidas; mientras que los ropajes presentan pliegues algodonosos, características éstas que comparte con otros escultores romanistas. El canon de sus figuras es más estilizado que la que muestran otras tallas de sagrarios, dando como resultado unas imágenes bien proporcionadas y de fuerte carácter clasicista, lo que nos hace pensar que salieron de la gubia del mismo Esteban de Velasco o, en cualquier caso, de la mano de algún oficial muy bien dotado. Las posturas de las tallas recuerdan a la estatuaria clásica y a las obras del maestro Juan de Anchieta, así como a los Evangelistas y santos que Marcantonio Raimondi grabó y difundió por Europa y que fueron una cantera inagotable para los artistas del siglo XVI.
En el relieve de la puerta del sagrario se representa la Última Cena (fig. 6). Como otras composiciones habituales en el Romanismo, adquiere la forma ovalada, con los personajes en torno a una mesa en perspectiva, tres de los cuales se disponen en primer plano, de espaldas y otros de perfil. Cristo, centrando la composición, tiene a su discípulo amado entre sus brazos, mientras que con la mano derecha levantada, se dispone a bendecir el cáliz que se halla sobre la mesa, instante que plasma el momento en el que queda instaurada la Eucaristía. Como fuente gráfica utiliza uno de los grabados de Alberto Durero donde se representa este mismo tema y también se inspira en grabados de Cornelis Cort que tanto éxito van a tener entre los escultores romanistas, aportando multitud de modelos. En la parte superior, unos niños desnudos descubren la escena abriendo un cortinaje, un detalle que también podemos ver en el sagrario de la catedral de Astorga, donde Gaspar Becerra empleó este recurso escenográfico, adelantándose al Barroco.

En los cuatro nichos del primer cuerpo se disponen las tallas de los cuatro evangelistas. La ubicación exacta de estas cuatro piezas ha debido sufrir modificaciones, ya que las posturas de las figuras rompen con la ley de la correspondencia tan en boga durante el Romanismo y tan respetado en otras obras de Esteban de Velasco, por lo que podemos asegurar sin temor a equivocarnos que estas imágenes de los evangelistas no están en su nicho correspondiente, dado que son esculturas que no tienen ningún sistema de sujeción al sagrario.

En el segundo cuerpo tenemos otro grupo de cuatro figuras, en correspondencia numérica con los evangelistas, que son los cuatro Doctores de la Iglesia: san Agustín, san Ambrosio, san Gregorio y san Jerónimo (figs. 7-10), fácilmente identificables porque visten con sus hábitos episcopales y cardenalicios y portan sus atributos. Éstos se encuentran bajo arcos de medio punto y son de un tamaño ligeramente inferior que el de los evangelistas, aunque todas rondan los $30 \mathrm{~cm}$ de altura. A pesar de la dificultad técnica que supone esculpir en un tamaño 


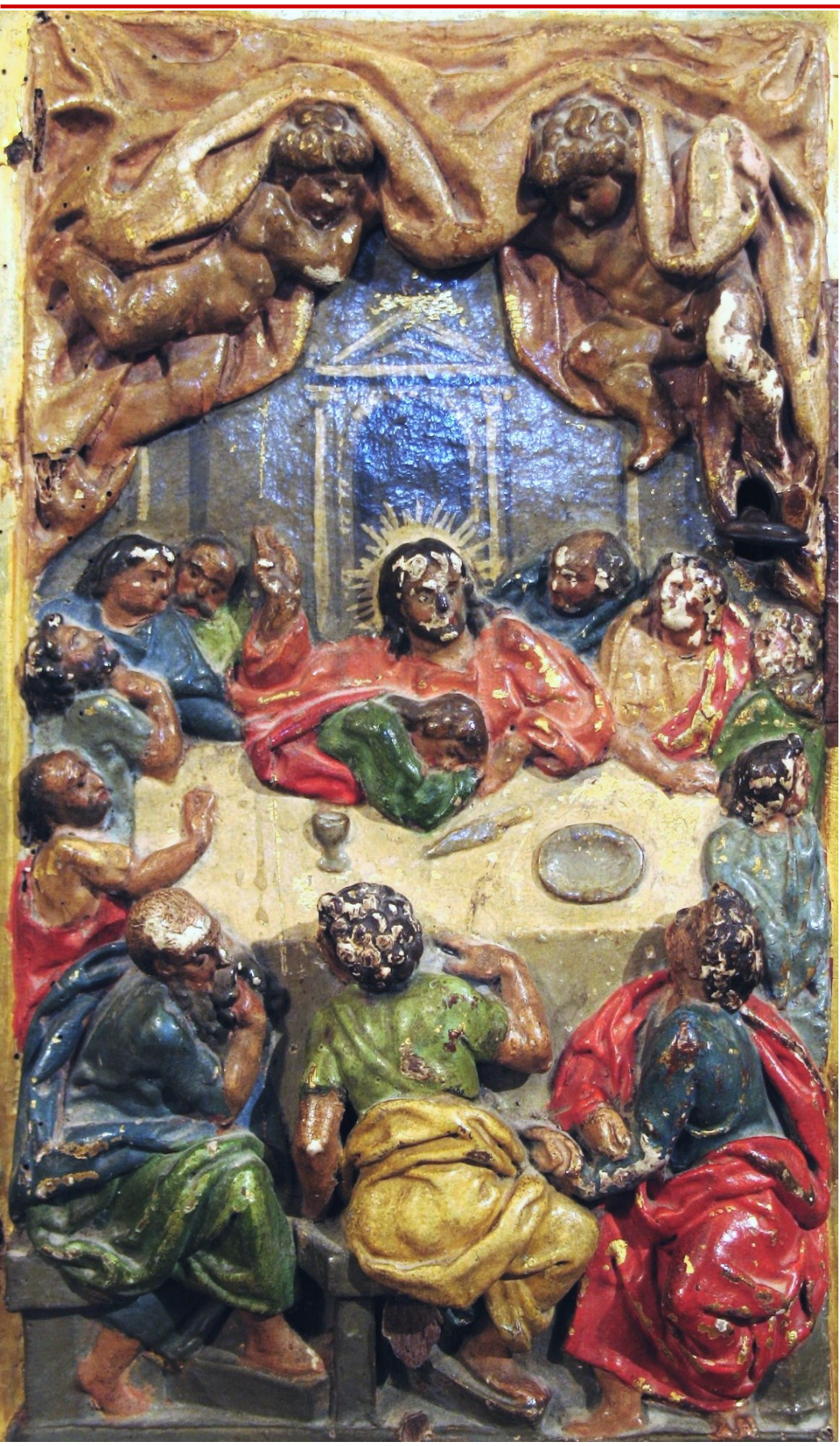

Fig. 6: Puerta del sagrario de Durana (Álava)

tan reducido -lo que es una singularidad de las esculturas de los sagrarios-, Velasco consigue mantener un canon y unas proporciones correctas y la "fiera" expresión de los rostros que caracteriza al Romanismo, así como una representación magistral de las telas, realizada con gruesos pliegues.

Sabemos que tanto la arquitectura como la escultura no se consideraban terminadas hasta que recibían el acabado de color y, en el caso del sagrario de Durana, dicha policromía fue aplicada por Diego Elías de Avena, pintor flamenco afincado en Vitoria-Gasteiz y autor de importantes policromías y de pinceladuras ${ }^{25}$. La tasación correría, años más tarde, a cargo de otro de los grandes policromadores de la provincia, Pedro Ruiz de Barrón en $1618^{26}$. Pero este sagrario sufrió una repolicromía en 1805 aplicado por Manuel Rico ${ }^{27}$, autor de afamados acabados de colores planos sobre bellas policromías contrarreformistas en Álava a principios del siglo XIX y que desgraciadamente desmejora el conjunto, ya que elimina los estofados $y$ los matices de color, además de ocultar parte de las tallas, como hemos visto en los relieves de las virtudes.

La policromía era un elemento indispensable en los sagrarios porque el revestimiento dorado les dotaba de un fuerte valor simbólico, pero hoy en día es difícil encontrar obras con la policromía contrarreformista que les corresponde, también llamada del Natural, consistente en tallos vegetales, niños desnudos y pájaros, realizada con sus característicos tres colores básicos $^{28}$. Aunque a través de unas desconchaduras de la repolicromía se

25 ECHEVERRÍA GOÑI, P. L.: “Contribución del País Vasco...”, op. cit., p. 92.

26 AHPA-AAHP. Prot. 2353, escr. Gaspar de Elejalde, año 1618, fols. 90r-91r.

27 BARTOLOMÉ GARCÍA, F. R.: La policromía barroca en Álava. Vitoria-Gasteiz, Diputación Foral de Álava, 2001, p. 283.

28 ECHEVERRÍA GOÑI, P. L.: Policromía del Renacimiento en Navarra. Pamplona, Gobierno de Navarra, 1990, pp. 236-241. IBID.: "Las policromías del complejo siglo XVI en el País 
pueden apreciar restos de estofados y esgrafiados originales, es imposible hacer una valoración de la policromía de este sagrario, al menos hasta que una restauración integral le devuelva su identidad de color.

\subsection{El mensaje del sagrario}

No podemos olvidar que estos sagrarios son portadores de un alto valor simbólico que se manifiesta en su forma externa de planta central que evoca el Santo Sepulcro, pero también en el programa iconográfico que contienen. La exaltación eucarística promulgada por Trento y la consecuente depuración de formas y contenidos llevada a cabo en las creaciones artísticas, se dejan notar no sólo en la tipología de los sagrarios, sino que también en su programa iconográfico, en tanto que forma, contenido y función van indisolublemente unidos y orientados en una misma dirección. Es bien conocido que la última sesión de Trento celebrada en 1563 se dedicó a las imágenes religiosas y en ella se determinó que el arte religioso debía ser un instrumento didáctico porque "por medio de las historias de nuestra redención, expresadas en pinturas y otras copias, se instruye y confirma el pueblo recordándole los artículos de la fe, y recapacitándole continuamente en ellos" ${ }^{29}$.

Sobre el discurso catequético que se desarrolla en este sagrario, debemos decir que, bajo una aparente sencillez, tiene un gran trasfondo teológico y sacramental. Comenzando la lectura por la parte inferior, vemos que en el

Vasco, Navarra y La Rioja", en FERNÁNDEZ GRACIA, R. (coord.): Pulchrum. Scripta varia in honorem $M \underline{a}$ Concepción García Gainza. Pamplona, Gobierno de Navarra, Universidad de Navarra, 2011, pp. 289-291. VÉLEZ CHAURRI, J. J. y BARTOLOMÉ GARCÍA, F. R.: La policromía de la primera mitad del siglo XVII en Álava. Pedro Ruiz de Barrón y Diego Pérez y Cisneros (1602-1648). Miranda de Ebro, Instituto Municipal de Historia, 1998, pp. 13-18. BARTOLOMÉ GARCÍA, F. R.: op. cit., p. 222.

29 Actas del Concilio de Trento, sesión XXV, diciembre de 1563. banco se ubican seis de las siete virtudes, unas figuras básicas para toda vida cristiana. En el centro del sagrario, en la puerta, se ubica la Última Cena o la Institución de la Eucaristía, escena que representa la presencia de la Eucaristía en el sagrario y que justifica el concepto de la transubstanciación. En los cuatro nichos del cuerpo principal se disponen los cuatro evangelistas agrupados sin establecer ningún tipo de jerarquía entre ellos. Estas cuatro tallas del primer cuerpo representan el testimonio directo de la Encarnación del Verbo y el sacrificio de Cristo, narrado en los evangelios que redactaron. Así, en los sagrarios romanistas podemos encontrar con frecuencia a los cuatro evangelistas como testigos de la vida terrenal del Hijo de Dios.

En el cuerpo superior se hallan los cuatro Doctores o Padres de la Iglesia que son los teólogos que definieron los dogmas y las doctrinas esenciales del catolicismo y que representan el fundamento de la fe, de ahí que su presencia en un sagrario se halle plenamente justificada, como muestra de que la doctrina se funda en una razón teológica. Además, en la época inmediatamente posterior a Trento, los Padres de la Iglesia suelen tener un mayor protagonismo en los programas iconográficos de los sagrarios y retablos porque su presencia refuerza la autoridad moral de la Iglesia. El de Durana no es el único sagrario que muestra a los doctores de la Iglesia, ya que también los encontramos en Pedruzo, recostados en el basamento, dando la base simbólica del sacramento; en Gereña ${ }^{30}$, obra de Pedro de Ayala de hacia 1606, están en el cuerpo superior flanqueando el expositor, y en esta misma ubicación los encontramos en Gordoa ${ }^{31}$, obra del taller de Salvatierra-Agurain.

30 ENCISO VIANA, E. (coord.): op. cit., p. 430

31 PORTILLA VITORIA, M. J.: op. cit., p. 463. 

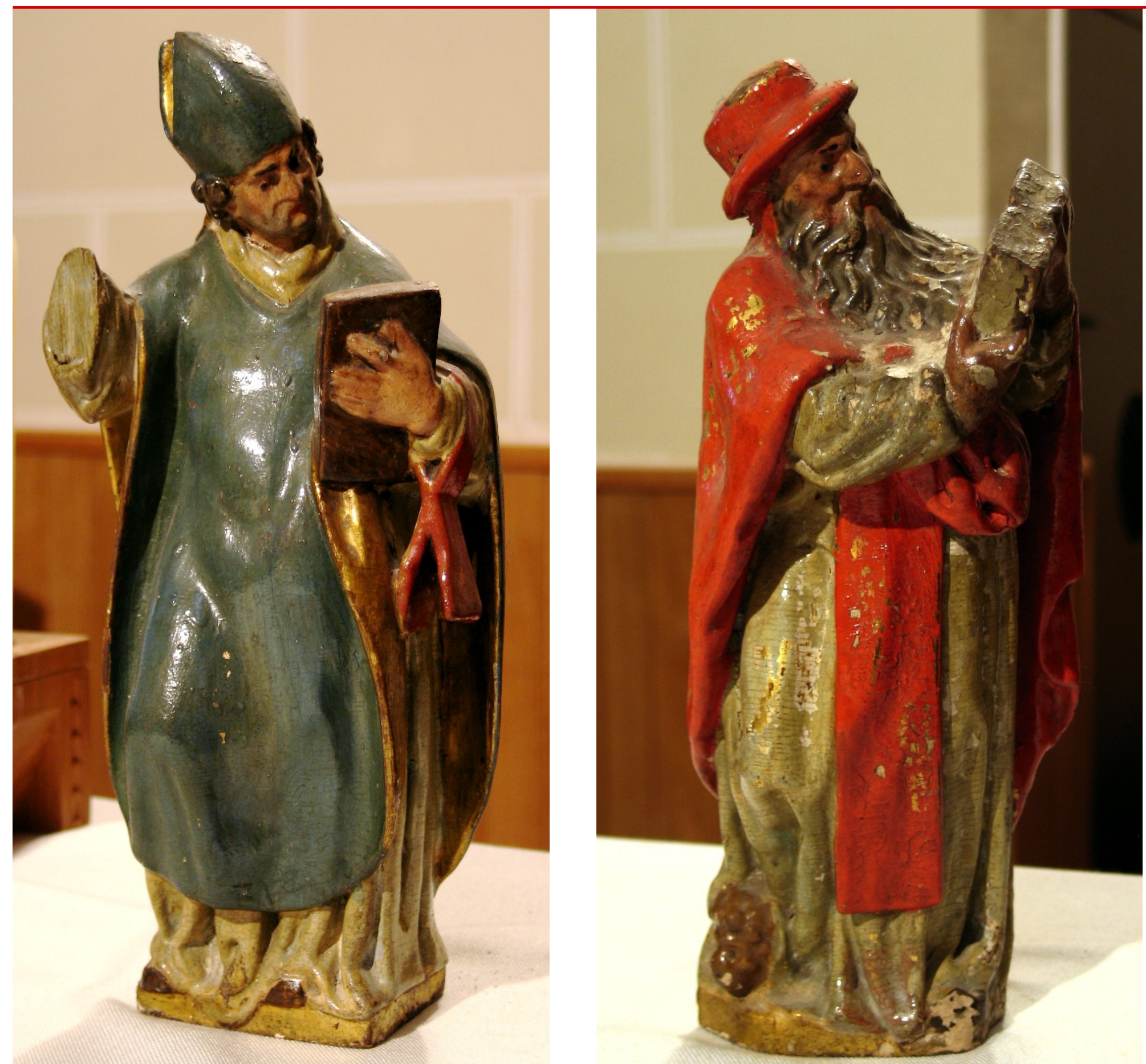

Figs. 7-8: San Ambrosio y san Jerónimo, padres de la Iglesia del sagrario de Durana (Álava) 
Figs. 9-10: San Agustín y san Gregorio Magno, padres de la Iglesia del sagrario de Durana (Álava)
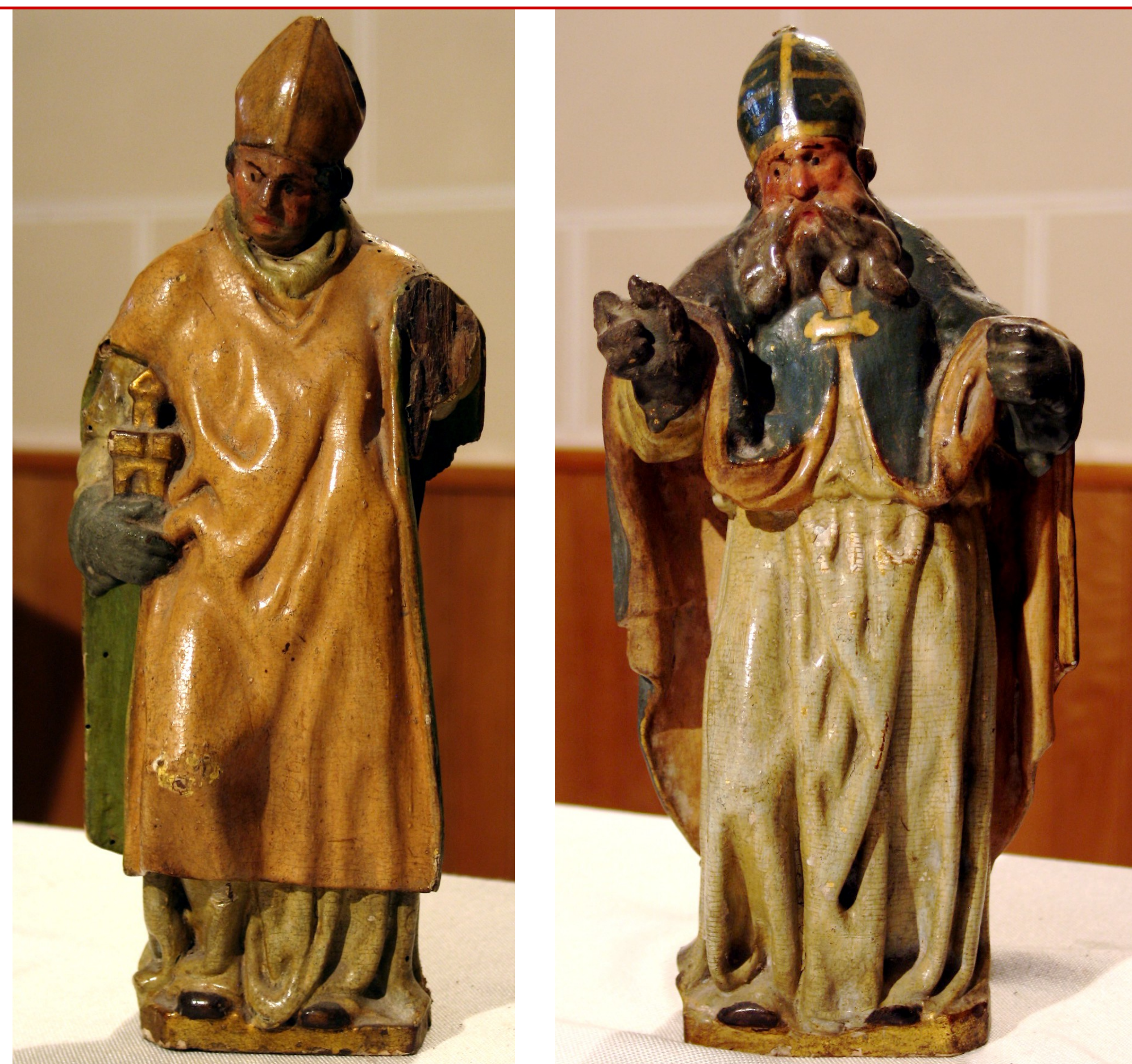
En este sagrario observamos que el discurso se organiza en torno a tres grupos de representaciones: las virtudes, los evangelistas y los Padres de la Iglesia. Por una parte, las virtudes, teologales y cardinales, que son las cualidades que infunde Dios en los humanos para que alcancemos el estado de gracia, están ubicadas en las partes estructurales de la base, y en este caso son un total de seis. Dos de ellas las identificamos con la Esperanza y la Fortaleza, y las demás, a pesar de no portar ningún atributo, podríamos pensar que son la Fe, la Prudencia, la Justicia y la Templanza, de tal manera que la única virtud que se quedaría sin figura alegórica sería la Caridad, la principal de todas. La razón de su ausencia es que la Caridad se identifica con la Eucaristía, ya que el sacrificio de Cristo en la cruz es el mayor acto de caridad y de entrega de ese amor de Dios que está presente en las almas. El cristiano, en el camino al estado de gracia y la vida eterna, además de practicar las virtudes se alimenta con la Eucaristía, que está presente en el sagrario con la luminaria, y cuya institución está representada en la puerta del sagrario.

Por su parte, los evangelistas enseñan la vida de Cristo, son depositarios de la verdad revelada, fueron testigos de ese sacrificio que se conmemora con la Eucaristía y, a través de los Evangelios que escribieron, conocemos la doctrina de la gracia explicada por Cristo en la Última Cena, presente en la puerta del sagrario. Precisamente sobre el concepto de la gracia versaron los principales debates del concilio de Trento, donde se aclaró la doctrina fundamentándose en los Padres de la Iglesia. Éstos son considerados los defensores de esa verdad revelada en los evangelios y la base teológica del sacramento, ya que lo explican, lo defienden y lo exponen. Lo mismo podemos apreciar en el sagrario de Durana, que, en medio de los cuatro Padres de la Iglesia está expuesto el mismo sacramento ante los ojos de los fieles.

Es evidente que en este sagrario podemos advertir, una vez más, que la elaboración de estos complejos programas implica profundos conocimientos teológicos que precisan de una sólida formación, especialmente fomentada tras Trento. Tal vez el carácter sacramental del programa y su mensaje de profundidad teológica hayan motivado la presencia de los Evangelistas y de los Padres de la Iglesia, santos todos ellos que no son de devoción popular sino de veneración en círculos más eruditos. En cualquier caso, queda claro que el mensaje de los sagrarios no está orientado a narrar la historia de la salvación para mostrársela a los fieles como ocurre en los retablos, sino que adoptan unos tintes más intelectuales y de carácter sacramental, más acorde con su función. Es decir, que el mensaje del sagrario no está orientado a la narración sino a la representación, algo que podemos considerarlo lógico en un mueble que los fieles observan desde una distancia. Pero, sobre todo, con este mensaje queda claro que los sagrarios tienen su propio programa iconográfico independiente del retablo y que son obras de plena autonomía tanto formal como iconográfica.

\section{CONCLUSIONES}

La función sagrada y la importancia litúrgica del sagrario permitía una mayor atención artística a estos muebles que no podían faltar en ninguna parroquia, y la mayor vigilancia reclamada, desde las diócesis, a los tabernáculos en los inicios de la contrarreforma preparó el terreno y fomentó su posterior desarrollo artístico.

La traza arquitectónica de este sagrario de Durana nos habla de un conocimiento profundo de los tratados arquitectónicos del Renacimiento por parte de Esteban de Velasco, que ponía en práctica no solo en los sagrarios, sino que, por extensión, también lo hacía en los retablos y los sepulcros que trazaba, unos conocimientos que no se advierten en la arquitectura construida, mucho más conservadora en sus estructuras. Este clasicismo tan habitual en las obras de Velasco se introdujo en Álava en los sagrarios a partir de los 70 del siglo XVI cuando el estilo romanista 
empezó a dar sus primeros frutos en las zonas de influencia de los talleres de Valpuesta y Miranda de Ebro, pioneros en la adopción de este renovado estilo tridentino, y llegará a su madurez en los dos siguientes decenios en la zona central de la provincia, de la mano de los talleres de Vitoria-Gasteiz y de Salvatierra-Agurain. A medida que nos acercamos al siglo XVII y sobre todo una vez traspasado el año 1600 las trazas de los tabernáculos se van complicando con la incorporación de trazas curvadas, estructuras turriformes con más pisos, cuerpos que sobresalen en planta, y en conjunción, también las esculturas aumentan en número y el programa iconográfico se enriquece. Esta evolución demuestra que el arte se va acercando al barroco, que se incorpora definitivamente en los sagrarios a partir de 1630 aproximadamente.

El sagrario de Durana es un perfecto ejemplo de esta madurez romanista de corte clasicista, por lo que la consideramos una obra modélica y un buen prototipo de la evolución artística en Álava. Su concepción arquitectónica como un edificio de planta central compuesto por elementos clasicistas constituye la vanguardia artística de finales del siglo $\mathrm{XVI}$, ya que presenta unas propuestas de origen italiano novedosas que son imposibles de ver en las obras de cantería. Ni plantas centrales ni los elementos manieristas descritos están presentes en la arquitectura construida contemporánea, inmersa aún en soluciones tardogóticas, por lo podemos considerar a los sagrarios como microedificios realmente modernos y vanguardistas que reflejan la evolución de los conocimientos artísticos.

En cuanto a la tipología, el tabernáculo de Durana es una de las primeras en estrenar la tipología de sagrario-expositor en esta época en Álava, que comienza su andadura al calor de Trento y que tendrá un espectacular desarrollo en los siglos posteriores. En esta pieza se aporta una acertada solución para que un mismo mueble custodie con seguridad la eucaristía y fomente su veneración con la exposición ante los fieles en su cuerpo superior, que tendrá una buena acogida en la microarquitectura eucarística de los años finales del siglo XVI y principios del XVII.
También es destacable el mensaje que este sagrario transmite a través de su calculado programa iconográfico, demostrando que los sagrarios son piezas independientes al retablo, que están destinados a la transmisión de un mensaje sacramental, más representativo que narrativo, y que por ello tienen una entidad propia. Además de estar concebidos como obras autónomas y tener un diseño individual, ya que cuentan con contratos específicos y propios, los sagrarios también son piezas en las que se aplican y experimentan las nuevas soluciones arquitectónicas, por lo que los podemos estimar como verdaderas obras de vanguardia.

Por todo ello consideramos importante llamar la atención sobre una obra tan significativa del estilo romanista en Álava como es el sagrario de Durana, integrado siempre, como otros sagrarios, en los estudios de retablos, pero que es una obra que destaca con luz propia sobre las creaciones artísticas de su ámbito y merecedora de la atención de la historiografía. 


\section{BIBLIOGRAFÍA}

AIZPÚN BOBADILLA, J.: “Ubicación de los enterramientos y el sagrario. El caso de Estella (Siglos XV y XVI)". Príncipe de Viana, no 228, año 64, 2003, pp. 91-126.

ANDRÉS ORDAX, S.: El escultor Lope de Larrea. Vitoria-Gasteiz, Diputación Foral de Álava, 1976.

: El foco de escultura romanista de Miranda de Ebro: Pedro López de Gámiz y Diego de Marquina. Valladolid, 1984.

ARIAS MARTÍNEZ, M.: "El diseño del sagrario contrarreformista: estructura formal, símbolo e iconografía”, en CALVO DOMíNGUEZ, M. (coord.): Camino de paz. Mane nobiscum domine. Santiago de Compostela, Xunta de Galicia, Consellería de Cultura, Comunicación Social e Turismo, S.A. de Xestión do Plan Xacobeo, 2005, pp. 71-87.

BALLESTEROS IZQUIERDO, T.: “El retablo del Santo Ángel de la Guarda en la Iglesia de San Pedro de Vitoria”,Kultura, 2a época, no 4, 1992, pp. 19-27.

BARRÓN GARCÍA, A. Á. y POLO SÁNCHEZ, J. J.: “Los tabernáculos para retablos en el Romanismo burgalés. García de Arredondo", en RUIZ DE LACANAL, Mạ D. y GARCÍA PAZOS, M. (ed.): La catalogación de retablos. Catalogación, restauración y difusión. Actas de los VIII Encuentros de Primavera en El Puerto. El puerto de Santa María, Ayuntamiento, 2007, pp. 243-278.

BARTOLOMÉ GARCÍA, F. R.: La policromía barroca en Álava. Vitoria-Gasteiz, Diputación Foral de Álava, 2001.

CASTIÑEIRAS, M.: "San Vicentejo de Treviño, un edificio excepcional en la encrucijada del tardorrománico hispánico", en GONZÁLEZ DE
VIÑASPRE GONZALO, R. y GARAY OSMA, R. (ed.): Viaje a íbita. Estudios Históricos del Condado de Treviño. Treviño, Ayuntamiento del Condado de Treviño, 2011, pp. 249-256.

DÍEZ JAVIZ, C.: “El escultor romanista Diego de Marquina (1542-1604)", López de Gámiz, no XXXII, 1998, pp. 15-60.

ECHEVERRÍA GOÑI, P. L.: Policromía del Renacimiento en Navarra. Pamplona, Gobierno de Navarra, 1990.

: “Contribución del País Vasco a las artes pictóricas del Renacimiento: la pinceladura norteña". Ondare, Cuadernos de Artes Plásticas y Monumentales, no 17, 1998, pp. 73-106.

: "Las policromías del complejo siglo XVI en el País Vasco, Navarra y La Rioja", en FERNÁNDEZ GRACIA, R. (coord.): Pulchrum. Scripta varia in honorem $M \underline{a}$ Concepción García Gainza. Pamplona, Gobierno de Navarra, Universidad de Navarra, 2011, pp. 283-292.

ECHEVERRÍA GOÑI, P. L. y VÉLEZ CHAURRI, J. J.: “La aportación de Esteban de Velasco al romanismo alavés", en ZALAMA, M. Á. y MOGOLLÓN CANO-CORTÉS, P. (coord.): Ars. Estudios de Arte e Historia en homenaje al Dr. Salvador Andrés Ordax. Valladolid, Universidad de Valladolid, Universidad de Extremadura, 2013, pp. 111-120.

ENCISO VIANA, E. (coord.): Catálogo Monumental Diócesis de Vitoria. Tomo IV: La Llanada alavesa occidental. Vitoria-Gasteiz, Obra Cultural de la Caja de Ahorros Municipal, 1975.

GARCÍA GUINEA, M. Á. y PÉREZ GONZÁLEZ, J. Mạ: Enciclopedia del Románico en el País Vasco: País Vasco. Aguilar de Campoo, Fundación Santa María la Real, Centro de Estudios del Románico, 2010. 
LÓPEZ DE OCÁRIZ ALZOLA, J. J.: “El Arte Románico alavés. La gran floración de iglesias románicas y la peculiar configuración de la Álava medieval", Jornadas Congresuales Homenaje a Micaela Portilla Vitoria. Vitoria-Gasteiz, Diputación Foral de Álava, Departamento de Euskera, Cultura y Deportes, 2007, pp. 131-140.

PORTILLA VITORIA, M. y EGUÍA LÓPEZ DE SABANDO, J.: Catálogo Monumental Diócesis de Vitoria. Tomo II: Arciprestazgos de Treviño, Albaina y Campezo. Vitoria-Gasteiz, Obra Cultural de la Caja de Ahorros Municipal, 1968.

PORTILLA VITORIA, M. J.: Catálogo Monumental Diócesis de Vitoria. Tomo V: la Llanada oriental y valles de Barrundia, Arana, Arraya y Laminoria. Vitoria-Gasteiz, Obra Cultural de la Caja de Ahorros Municipal de Vitoria, 1982.

RAMÍREZ MARTínEZ, J. M.: "El relicario como destacado mueble litúrgico", en LABARGA GARCÍA, F. (ed.): Festivas demostraciones. Estudios sobre las cofradías del Santísimo Sacramento y la fiesta del Corpus Christi. Logroño, Instituto de Estudios Riojanos, 2010, pp. 197-214.

: Los talleres barrocos de Escultura en los límites de las provincias de Álava, Navarra y La Rioja. Logroño, Diputación Provincial, 1981.

TABAR ANITUA, F. (coord.):Catálogo Monumental. Diócesis de Vitoria. Tomo X: Los valles occidentales entre el Zadorra, el Ayuda y el Inglares. La villa de La Puebla de Arganzón Vitoria-Gasteiz, Fundación Caja Vital Kutxa, 2011.

VÉLEZ CHAURRI, J. J. y BARTOLOMÉ GARCÍA, F. R.: La policromía de la primera mitad del siglo XVII en Álava. Pedro Ruiz de Barrón y Diego Pérez y Cisneros (1602-1648). Miranda de Ebro, Instituto Municipal de Historia, 1998.
VÉLEZ CHAURRI, J. J. y ECHEVERRÍA GOÑI, P. L.: "El arte religioso del Renacimiento y el Barroco en Valdegovía", en VÉLEZ CHAURRI, J. J. (ed.): Las tierras de Valdegovía. Geografía, Historia y Arte. Actas de las Jornadas de Estudios sobre Geografía, Historia y Arte en Valdegovía. Vitoria-Gasteiz, Diputación Foral de Álava, 2003, pp. 125-177. 